\title{
The Efficacy of a PD Program on Enhancing On-The-Job Teaching Skills
}

\author{
Gihan Sidky ${ }^{1}$ \\ ${ }^{1}$ School of Education, Cairo University, Cairo, Egypt \\ Correspondence: Gihan Sidky, School of Education, Cairo University, Cairo, Egypt. E-mail: \\ gihansidky@hotmail.com
}

Received: June 8, 2017

Accepted: July 11, $2017 \quad$ Online Published: October 28, 2017

doi:10.5539/ies.v10n11p63

URL: https://doi.org/10.5539/ies.v10n11p63

\begin{abstract}
This study assessed the methods of teaching English course taught at the general diploma at the college of Graduate Studies in Education, Cairo University in light of English teachers' needs and expectations. The Methodology course was reconstructed using the premises of students centered teaching techniques and taking into consideration what is identified by teachers as their basic needs to improve teachers' linguistic skills and to allow teachers to get acquainted with recent teaching techniques that focus on enhancing the qualifications of the graduate students. The participants in the study were 50 English teachers who graduated from faculties of tongues and arts, English major. They were studying to get a general diploma in education. Some of them had different years of English teaching experience and others never taught in their life. Three instruments were implemented to elicit teachers' needs from the methods of teaching English course: a pilot study to elicit teachers' needs and expectations of the methodology course and a directed questionnaire that resulted in a number of suggested topics to be included in the methodology course. A pre and a posttest were administered before and after the implementation of the program to record changes in teachers' knowledge and skills due to the application of the revised course. Teachers' responses showed that the participants were dissatisfied with the topics and applications offered by the methods of teaching English course in its first form and suggested a number of topics and applications to be added to satisfy their future needs and expectations. The program was revised and reconstructed in light of teachers' needs and it was taught for two semesters during the academic year 2014/2015. The results showed a noticeable improvement in teachers' knowledge and skills, which were manifested in teachers' responses to the posttest.
\end{abstract}

Keywords: professional development, teacher quality, teacher education reform, in-service teacher training, students' needs, teachers' needs, expectations

\section{Introduction}

For decades teacher quality has become an issue of concern to those who are interested in education worldwide. The approaches to teacher quality are varied and so are the results. Two prominent models that dominate research on teacher quality are the input and output models. The input model focuses on the preparation of teachers, their knowledge of English and their GPA. However, recent trends on teacher quality assess teachers' performance in terms of teacher's practices, teacher tracking, retention and student achievement, which are based on an output model.

Assuming that teacher quality has a tremendous influence on student achievement resulted in increased attention to research on teacher quality (Boyd, Lankford, Loeb, Rockoff, \& Wyckoff, 2007; Clothfelter et al., 2004; Provasnik \& Young, 2003; Rice, 2003; Rivers \& Sanders, 2002). Proponents of the belief that having a qualified teacher equals increased student achievement believe that investment in programs that produce highly qualified teachers are worthwhile ((Ferguson, 1991; Ferguson and Ladd, 1996; Strauss and Sawyer, 1986).

In sum, the present study is located in a framework, which focuses on teacher quality as a central issue in raising the quality of education in general and English teaching in specific. Paying much attention to the quality of professional development courses offered for English teachers would result in better students' achievement rates. Hence, it is imperative that we revise the standards on which teacher education programs are based in light of teachers' needs, students' needs and expectations and in light of standards imposed by recent trends in education and market requirements of graduates of schools of education and other colleges, who aspire to work as teachers 
at different stages. Thus, the current professional development program adopts an output model in its reconstruction of the methodology course at hand, which focuses on enhancing the qualifications of the English teachers as its target.

\section{Literature Review}

Teacher quality has occupied a central position worldwide lately. There is a consensus that teacher quality is very important, however what defines a highly qualified teacher is still controversial to a great extent and how to prepare such teacher is even more debatable.

As previously mentioned, output models focus on student achievement, but they may encompass actual classroom practices, retention, professional involvement, and contextual factors at the school environment.

An example of a study that is based on an output model is done by the Teacher Quality Initiative (Darling-Hammond \& Bransford, 2005). The following list resulted from interviewing and observing teachers, whose students are considered high achievers, for a whole year:

- Students' expectations were highlighted and students' previous works were used as models to guide students' future work.

- Students' projects and presentations were displayed everywhere.

- The teachers moved around the class and varied their teaching techniques and supervised all students' activities.

- Classroom arrangement allowed multiple activities to take place simultaneously.

- Students were urged to think critically, ask questions, and have discussions among themselves and with the teacher.

- Teachers were well prepared and the lessons were clearly organized. Accessibility of materials was evident, and class time was always respected.

Garcia et al. (2006) highlight that students in high schools have developed criteria for assessing highly qualified teachers. Through a study that lasted for several months in which the students had weekly meetings, readings, writing assignments, and research to raise their awareness about teacher quality, they came out with the following criteria, which include: creating safe, respectful, culturally conducive, and responsive learning communities; to communicate with students' families and communities; to have high expectations for students; and to adapt their teaching to suit their students' learning styles.

The attention to teacher quality has increased greatly in the final decades of the twentieth century. In America, every state raised the standards for pre-service teachers, such as higher grade point averages, majors in content areas, tests for teacher's knowledge and skills, harder requirements for permanent certification, and national accreditation of teacher education programs (Zumwalt \& Craig, 2006). Teacher quality has been defined in light of teachers' academic achievement, which are reflected in their SAT scores, college GPA, and transcript quality in addition to teacher education programs, graduate or undergraduate status, and accreditation by national bodies (Buck \& O'Brien, 2005). Also the use of nationally normed teacher tests and individual state test scores has increased as other indicators of teacher quality (Rudner, 1988; Tanner, 2003).

At the beginning of the twentieth century there was a tendency towards raising the standards for teachers. Throughout the century efforts continued sometimes the focus was on teachers' inherent abilities and in other cases on the preparation teachers get. These efforts resulted in many reports that were published in the 1980s. One important report that led to the emergence of many reform movements is "A Nation at Risk: the Imperative for Educational Reform (National Commission on Excellence in Education, 1983). Among reform movements that followed are the Carnegie Task Force on Teaching, the Holmes Group, and the National Commission on Teaching and America's Future.

This increased attention that emerged in the USA between 2000 and 2005 to teacher quality resulted in many reports and studies (Cochran-Smith \& Fries, 2005). The U.S. Congress assigned the National Research Council to undertake a research on teacher preparation programs to assess the compatibility of such programs with recent research on high quality teaching (National Research Council, 2006). The Carnegie Corporation collaborated with eleven colleges and universities to initiate research based teacher education program. Its objective is to prepare high quality teachers (Teachers for a New Era, 2005). As both the public and policy makers in America believed in the necessity of having a qualified teacher, which they assumed greatly influenced student achievement and life chances. This general attitude led to having a mandate in the 2001 No Child Left Behind (NCLB) legislation, that every core subject classroom have a "highly qualified" teacher by 2005-2006). 
As English has occupied a central place as one of the widely spoken languages worldwide as a foreign or second language, many studies focused on the effectiveness of professional development programs that help English teachers become more competent in English teaching.

Hye-Sook (2014) explored the interaction between professional development and professional learning communities on improving the educational experiences of English learners. The research highlighted the professional development experiences of secondary school English teachers in Maryland and their viewpoints regarding characteristics of professional development programs that are most effective in improving their professional knowledge and attitudes toward PD. It also emphasized the influence of professional learning communities on professional development outcomes by allowing the sustainability of learning for teachers. The study combines Garet et al.'s (2001) framework of effective PD and Olivier and Hipp's (2010) model of PLCs. The use of these two frameworks combined underlies the relationship between PD and PLCs, and the influence of these experiences on teachers' improved knowledge and attitudes toward PD. 100 teachers participated in the survey and 9 participated in the interview, and data from the surveys and interviews were analyzed using a mixed method approach that combined quantitative and qualitative research methods. Data analysis coincided with Garet et al.'s (2001) findings that professional development programs that focused on enhancing content knowledge and was compatible with teachers' learning experiences led to positive attitudes toward PD in addition to enhancement in their knowledge.

Lauren (2012) claims that most English teachers have not had enough in-service training in adjusting their teaching to suit their students' needs. Her research investigates a PD program that aims at preparing English teachers in content and oral language. The study examines the steps of Desimone's (2009) logic model of effective PD. The model suggests three steps: First teachers experience PD, secondly they gradually increase their knowledge and skills, finally enhance their teaching practices, which consequently affect their students' outcomes. For three years K-2 teachers took part in math and science PD, which integrated three models that were changing every year as a result of teachers' assessment. Each PD model incorporated content and oral language. The impact of the program was measured through 1) examining how teachers' participation in each model of the program influenced a) participating teacher's perceptions of the importance of oral language production strategies, b) Teachers' teaching practices, and c) students' achievement. 2) Investigating the positive effect of blended online-blogging and face- to- face model, and 3) making a comparison among the models to identify effective learning environments for English teachers. The results pointed out that teachers showed greater perception of the value of oral language learning in relation to content lessons. This was manifested in their inclusion of the oral language production strategies introduced in the PD program in their teaching. When interviewing teachers, teachers reported that students' progress in the oral language was due to the program's instructional strategies. Classroom observations proved teachers' use of instructional strategies implemented in the program in their teaching. The results showed increase in participants' math and English language arts state test scores at treated schools in comparison to scores from non-treated schools in the same district. Moreover, an increase in the teachers' collaboration, professional reflection, and personal support were evident due to the implementation of the blended model.

Brown (2007) examined public school teachers' points of view regarding the effect of taking part in professional development programs that aim at supporting them to be more knowledgeable in terms of strategies and techniques to cope with their various classrooms' educational needs. The study participants involved $104 \mathrm{~K}-12$ public school teachers from one school district in Michigan. The teachers filled a survey on Bilingual Education and Professional Development, to elicit information related to bilingual education and the use of PD to help ESL students learn English. The first part of the survey includes 45 items that test perceptions of professional development and bilingual education. By using a principal components factor analysis; 12 subscales appeared to meet the study research questions: professional development, preparedness to teach English language learners (ELL), professional development of teachers of ELL students, the value of professional development for teaching, meeting the needs of ELL students, understanding ELL development, ELL student placement, time in ELL classes, lesson content, professional development content, student outcomes, and professional development topics. Results indicated that teachers' perceptions of professional development and bilingual education were positive. But their perceptions of ELL students' educational placement were negative. Teachers' perceptions differed among the three levels with elementary teachers having more positive perceptions than teachers at the other levels. The study highlights that the number of ELL students were significant predictors of teachers' perceptions of their preparedness to teach ELL students. The study also underlies that years spent in their present 
school district and in education in general was another predictor of students' outcomes. They conclude that professional development seems to fulfill its goal of preparing teachers to work with ELL students. They explain the negative relationship between years of experience and teachers' perceptions of their preparedness to teach ELL students as an indicator of a need to help them work effectively with ELL students.

Shuang-Mei (2011) explores the ideal environment of the professional development of college English teachers in Hunan province in China. Using questionnaire and interviews and adopting the premises of the theoretical framework of learning organization theory, "Teacher from the perspective of learning organization refers to the process of teachers' achievement of personal mastery through improving mental models, establishing shared vision and team learning, and cultivating systems thinking". The study assesses the current state of college English teacher professional development and the factors that affect their professional development. The participants include 65 college English teachers from 5 colleges and universities in Hunan province. The findings of the study indicate that the ideal environment for English teachers involves: 1) teachers' strong commitment for self-development; getting support, guidance from school leadership, positive academic atmosphere, school-based academic activities, and having continuous communication among teachers. 2) College English teachers were found to be conscious of their professional development needs, innovative and have systems thinking; however the harmony between the individual's vision and team vision was not completely established. 3) In addition to teacher factors, induction, welfare fund, and promotion of professional technical titles were found to be among the major factors that affect college English teacher professional development. The study recommends cultivating a culture characterized by learning organization at colleges to promote professional development for English teachers.

Zhi-Ying (2010) examined the reasons for teachers' lack of enthusiasm about professional development, and offered some solutions and suggestions. The research aimed at contributing to the professional development of junior high school teachers in China. Through needs analysis of junior high school teachers regarding professional development, two prerequisites were found to effective needs, which are having the desire and capabilities to reach their professional goal. In other words, teachers' lack of enthusiasm could be manifested in two aspects: 1) capable but not aspiring, which could be traced to three factors: underestimating the importance of English, lack of recognition for teaching as a profession, and the devaluation of relearning English. (2) Aspiring but not capable. This is manifested in: wanting to enhance their skills but not finding good chances, time, and the incapability for doing so for a reason or another. The study concludes that some reasons for this lack of enthusiasm are common to all teachers; others are specific to English teachers. The first could be summarized as follows: inappropriate pre-service and in-service training programs, exam-oriented education culture, living and working conditions of teachers, the unfair evaluation system for teachers. The reform suggestions the study proposes include: reforming the syllabus of the pre-service training for English teachers, working on student teachers' programs so they establish firm foundation before they start their career, improving in-service teacher training, enhancing the efficacy of training implemented by individual schools, and enabling teachers to achieve their full potential by creating links among schools.

In the Arab world, the situation of English teaching and learning is even worse as both teachers and students struggle in their efforts to master a language that is completely different from their mother tongue. Besides, inadequate teacher training, insufficient resources, and a curriculum stuffed with information and few chances for students to apply what they have learnt or to use the language in authentic settings, and working for the exam are among the common persistent problems in our schools; to name just a few. In what follows the researcher is going to give an overview of studies that were conducted in different Arab countries; namely Saudi Arabia, United Arab Emirates, Jordan and Lebanon.

Javid (2014) elicited the opinions of Saudi EFL students in relation to the personality and ability characteristics of an ideal English teacher, the participants pointed out that both aspects were important. The following characteristics were in their points of view of great value: those who master the language, well-organized, cope with students' levels, answer students' questions, give clear instructions, specify assessment procedures, give enough examples, inspire students to be lifelong learners, use adequate teaching aids and a variety of teaching techniques. As for the personality characteristics, the participants highlighted the following as essential: those who make learning fun, have the ability to involve students in academic content, fair, explain well, committed, flexible, understanding, encourage students to participate actively in class activities, and discover their talents and who are available after class time are the most liked by study participants.

Orr reported that the privatization of education and the pressure to teach English in early stages of students' lives were more prominent in Lebanon than in other Arab countries. The study sheds light on English language teacher education in Lebanon and elicits the perceptions of English language teachers on the usefulness of their 
training. The tools used included a survey of 715 teachers and four semi-structured interviews, three with teachers and one with an official from the Ministry of Education. The results pointed out a number of issues, among which the low perceptions held by many teachers towards the pre- and in-service training they got, which they thought was due to the varied contexts that exist in the educational system in Lebanon, which is a mix of the private and the public education, which they thought, made it difficult for teachers training to be immediately applicable. The study recommends that English language teacher training focus on developing the critical reflective skills for teachers through utilizing the knowledge of experienced teachers. This in turn, the study assumes, will allow teachers to consciously apply knowledge and practice in any situation they encounter (2011).

Albaiz suggested the use of peer-observation of learning and teaching (POLT) approach in assessing English teaching in higher education institutes in Kingdom of Saudi Arabia (2016). The study involved 107 English teachers who teach in institutions in higher education in Saudi Arabia. POLT adopts the tenets of the reflective practice model, which involve peer-observation as a teaching technique (Chong \& Cheah, 2009). The model applies a number of steps: First the reconceptualization of one's experience, acceptance and analysis of feedback, and assessment of one's skills, knowledge and attitudes (Kohut, Burnap, \& Yop, 2007). The model includes a dialogue of thinking or doing that aims at enhancing ones skills. Donnelly (2007) suggests three elements that characterize the model: inquiring or reconsidering hypotheses, thinking of alternative points of view, and believing that modification in concepts form new meanings. This process results in transformative learning. It also entails sharing ones reflection, which leads to teachers gaining key skills that, ensures high quality teaching and learning (Darling-Hammond, 2006).

POLT is also based on the self-efficacy theory. Self-efficacy beliefs are influenced by a number of factors among which is mastery (Minott \& Young, 2009). When a teacher believes strongly that his/ her teaching has been successful, then their self- efficacy beliefs increase (Coskun\& Daloglu, 2010), whereas failure promotes a sense of inadequacy, which leads to low self-efficacy beliefs, especially if failure takes place in the early stages of learning (Harford \& MacRuairc, 2008). As people do not only learn through direct experience, observation can play a major part in influencing ones self- efficacy beliefs (Peacock, 2009). As the observation of a person undertaking a task gives guidance and develops the observer's self-efficacy. The study indicated noticeable enhancement in the quality of English learning due to the use of (POLT) (Albaiz, 2016).

Belhiah and Elhami (2015) questioned the effectiveness of using English as a medium of instruction (EMI) in the Arabian Gulf. The study focused on six universities in major cities in Arab Emirates and examined the perceptions of 500 students and 100 teachers about the use of English as a medium of instruction to teach subject matter. The participants responded through questionnaires and structured interviews. Results suggested the implementation of a bilingual curriculum in which both Arabic and English are used as a media of instruction, in order to improve students' biliteracy skills and help students preserve their identity and culture.

Alhabahba et al. (2016) urged for a needed reform in English teaching in the Arab world. The longitudinal data they presented highlighted a number of issues that need to be treated in the Arab world in general and in Jordan specifically, among which teacher centeredness and focusing on the textbook rather than developing lifelong strategies. The study calls for developing national standards for English language professional development that is based on sound research. The paper also underlies the need to benefit from observing and reviewing current practices.

A number of countries introduced English at the elementary stage, one of which is Taiwan. This study followed the announcement of the Ministry of Education (MOE) in Taiwan introducing English courses at the elementary stage in 2001. The study explored English teachers' practices and beliefs concerning the Elementary English Education (EEE) program. 150 elementary English teachers in Taiwan responded to a survey that was used to measure participants' practices and beliefs toward the implemented EEE program. Analyses of seven variables were done: teachers' qualifications and training, materials, teaching methods, assessment policies and practices, content/curriculum of English, environment, and culture. The results of the surveys revealed that teachers thought they had the qualifications to teach elementary English, but didn't believe this was the case with all teachers in the field. They noted too few professional development programs and little support from the government and schools. Regarding materials, teachers believed that they have the right to choose their own materials; most materials were practical and included technology. As for teaching methods used, teachers reported using teaching methods compatible with students' abilities and selected suitable activities. Concerning assessment, teachers used various assessment techniques and believed learning outcomes could be enhanced if alternative assessments are used. As far as content/curriculum is concerned the participants believed the focus in English teaching was on listening and speaking. They recommended that students' interests and enhancing their self-confidence need to be top priorities in English teaching curriculum. Environment; participants suggested 
that English teaching should take place at least twice a week, however it was reported that this standard was not achieved in most schools. There was an agreement among participants that English needs to be introduced in lower grades than fifth grade. Regarding culture, participants thought both the American and Chinese cultures need to be introduced in the curriculum to facilitate English learning. Finally, recommendations centered on increasing the number of qualified teachers, introducing more teacher qualification policies, and classifying learners according to their language levels. There was a positive attitude toward MOE's rapid implementation of EEE program as a response to elementary students' needs for English learning (Ching, 2002).

Other studies suggested immersion of learners as an alternative approach to teaching English. Young (2013) attempted to specify the professional needs of pre-service English immersion teachers in Korea. The objective of the study was to identify the main components of English immersion teacher preparation programs. Immersion in this study is based on an assumption that students' studying subject matter in English would enhance their motivation and their English language proficiency. The study concluded that among the main factors that contribute to a successful immersion program is having qualified teachers who are competent in the language and are well trained in teaching the subject matter in English, in addition to the establishment of an immersion model that suits the English language education environment in Korea.

Plavin (2004) studied the factors that influenced the retention of newly qualified primary English teachers in Israel. The study is qualitative; it involves three case studies of newly qualified English teachers using semi-structured interviews and a sample of 19 participants who were involved with the induction experiences of the teachers. Data revealed a strong link between retention, mentoring and induction. The study pointed that the factors that influenced retention rates of newly qualified English teachers were: the demands of teaching English, the status of teachers, and the interpersonal relationships in the school. In addition to these factors, the study highlighted that it is necessary to enhance the quality of induction support, and having a stronger induction link between the colleges and the schools is considered crucial in meeting the newly qualified English teachers' needs and improving their retention in schools.

In Japan the Ministry of Education, Culture, Science, Sports, and Technology undertook reforms that enabled primary schools to launch English education in 2002. As public elementary school teachers in Japan are not certified, the government took an important initiative when it invited native speakers of English to assist non-native elementary school teachers in teaching English, which posed a number of questions: "Who is more qualified to teach English, homeroom teachers or native English speakers? In case they will teach together, how would they collaborate? A study attempts to answer previously mentioned questions through examining a collaborative EFL model. The research adopts an ethnographic approach; which makes use of classroom observations, interviews, and surveys with $4^{\text {th }}, 5^{\text {th }}$ and $6^{\text {th }}$ grade students and their teachers. Findings indicated that students believe that it is beneficial to learn from both NS and NNS English teachers and perceived the presence of a bilingual teacher as necessary and crucial in English language program (Tanaka, 2008).

Lam (2011) explored the influence of Vietnam's Globalization on the policies of national language education and training programs for English teachers at the University of Pedagogy. The study showed a noticeable impact of policy changes on teacher training programs along a number of domains, such as program structure, student enrolment, faculty credentials, and curriculum content. The structure became more flexible that allows adding a program design with different models to cope with the increasing demand for English teaching. Due to the new quotas set by the government, the number of student teachers enrolled in English language instruction increased tremendously. The quality of faculty was greatly influenced by the increase in credentials required for English teachers, which mounted to MA in TESOL.

\section{The Present Study}

The English teachers who are studying in the general diploma at the college of Graduate Studies in Education, Cairo University are complaining about the English methods course. They claim that it does not meet their needs. They find it unsatisfactory as it does not cover what they define as their basic needs as language teachers. In other words, the current study seeks to answer the following questions:

1) What are the basic needs of the English teachers of the current methods of teaching English course?

2) What are the main components that need to be included in the English methods course in order to meet the needs of the English teachers?

3) What is the effect of the newly implemented English Methods course on teachers' knowledge and skills of teaching? 


\section{Method}

This study uses quasi experimental approach in data collection and analysis. A pre-test was applied to assess teachers' knowledge and skills before the implementation of the program at hand. The researcher elicited teachers' expectations and needs through administering a pilot study and a questionnaire that aimed at getting teachers' viewpoints on the English methods of Teaching course and eliciting their suggestions which were used to review course objectives and components in light of these needs. After the reconstruction and application of the new methods course, a posttest was administered to measure enhancement in teachers' knowledge and teaching skills.

\subsection{Participants}

The study participants consist of 50 English as foreign language (EFL) teachers who were enrolled in the general diploma during the academic year of 2014/2015. They work in the primary, preparatory, and secondary stages. Most of them are graduates of faculties of arts, different universities, and some from faculties of tongues, Ain Shams University, and they were all either planning to teach English or teaching. Their years of experience were varied, as they ranged from zero experience to more than twenty years of teaching English in public, private and international schools. Their purposes for taking the diploma were also varied, as some of them needed to add to their teaching experience especially that they graduated from colleges other than education, and others needed the certificate to get promoted or to have better work chances.

\subsection{Instruments}

1) A pilot study was administered prior to the implementation of the methodology course to elicit the topics that teachers expect to find in the methodology course based on their needs.

2) A directed questionnaire that was based on the needs elicited from the pilot study was applied. The items the participants mentioned in the pilot study were written in a form of a list and the participants were asked to arrange them according to their importance to them. Data was analyzed and the items that were repeated by a large number of participants were used in designing the methods of English course. The main target was to identify teachers' needs based on their responses to the pilot study and the directed questionnaire, arranging these needs according to their importance to the teachers, and building the professional development program in light of these needs taking into consideration students- centered teaching approaches and based on an output model.

3) Pre and posttests were administered before and after the implementation of the new methods of English teaching course to determine the gains attained if any in teachers' knowledge and skills. The test included 10 situations that represent challenges that teachers might encounter in their daily teaching experiences. Teachers were asked to write their comments on the way they think they would handle such situations in reference to their readings in the Methods course. The 10 items were distributed as follows: 2 items for pronunciation, 2 for grammar, 1 for vocabulary, and 5 items for students- centered teaching techniques that focus on having clear objectives, using authentic activities, brainstorming, role play, movies, presentations, group work, error correction constructively, and finally applying effective classroom management techniques. Students were given one mark for correctly identifying the problem, and one mark for suggesting a solution to the problem posed. Total marks for each domain were calculated and listed in a table. These marks represented the increase in the knowledge and skills gained by participants in the study in relation to the concepts presented in the course.

4) The pilot study, the questionnaire and the pre and posttests were given to jury to assess their validity and reliability.

Table 1. Reliability Statistics (Cronbach's Alpha .845)

\begin{tabular}{lcc}
\hline Ver & Cronbach's Alpha & All Cronbach's Alpha \\
\hline Pronunciation & .796 & \\
Grammar & .609 & \\
Vocabulary & .776 & .845 \\
Methods & .795 & \\
\hline
\end{tabular}

\subsection{Implementation}

The aims of the program are based on the needs of the participants as identified in the pilot study and the 
directed questionnaire administered at the beginning of the semester. Analysis of teachers' responses to the pilot study indicated that most participants assigned great value to students-centered teaching approaches, teaching language skills, emphasizing pronunciation, vocabulary, and grammar. They also expressed their need for classroom management techniques; dealing with behavioral problems inside the classroom, such as discipline, violence, etc. Also, the participants highlighted the need for being aware of students' developmental emotional and psychological characteristics and how to deal with them in the classroom. Priority was also placed on interactive activities and their applications in the classroom, how to deal with students' individual differences and various learning styles, addressing students' higher order thinking skills, such as problem solving, critical thinking, etc., developing learners' four skills; listening, speaking, reading and writing. Planning for teaching was also given high priority, and how to create a supportive, motivating, enriched and safe learning environment. Course goals include the adoption of an outlook to the classroom as a learning community that needs to be safe, inclusive, motivating, and enriched, encouraging learners to develop an attitude and ability that prompt them to become lifelong learners, to provide appropriate scaffolding that help students advance beyond their current developmental stage, and that encourages students to have self confidence that enables them to enhance their language fluency through peer and group activities, discussions, team projects and presentations, etc.

\section{Statistical Results and Discussion}

Table 2. Correlation of the variables of the test using Pearson

\begin{tabular}{lcccccc}
\hline Variable & & Pronunciation & Grammar & Vocabulary & Methods & Total \\
\hline \multirow{4}{*}{ Pronunciation } & Pearson & 1 & $.705^{* *}$ & $.323^{*}$ & $.566^{* *}$ & $.697^{* *}$ \\
\cline { 2 - 7 } & $\mathrm{Sig}$ & & .000 & .022 & .001 & .000 \\
\cline { 2 - 7 } Grammar & $\mathrm{N}$ & 50 & 50 & 50 & 50 & 50 \\
\hline & Pearson & $.705^{* *}$ & 1 & $.308^{*}$ & $.654^{* *}$ & $.667^{* *}$ \\
\cline { 2 - 7 } & $\mathrm{Sig}$ & .000 & & .030 & .000 & .000 \\
\cline { 2 - 7 } & $\mathrm{N}$ & 50 & 50 & 50 & 50 & 50 \\
\hline \multirow{4}{*}{ Vocabulary } & Pearson & $.323^{*}$ & $.308^{*}$ & 1 & $.600^{* *}$ & $.691^{* *}$ \\
\cline { 2 - 7 } & $\mathrm{Sig}$ & .022 & .030 & & .000 & .000 \\
\cline { 2 - 7 } & $\mathrm{N}$ & 50 & 50 & 50 & 50 & 50 \\
\hline \multirow{3}{*}{ Methods } & Pearson & $.566^{* *}$ & $.654^{* *}$ & $.600^{* *}$ & 1 & $.786^{* *}$ \\
\cline { 2 - 7 } & $\mathrm{Sig}$ & .001 & .000 & .000 & & .000 \\
\cline { 2 - 7 } & $\mathrm{N}$ & 50 & 50 & 50 & 50 & 50 \\
\hline \multirow{3}{*}{ Total } & Pearson & $.697^{* *}$ & $.667^{* *}$ & $.691^{* *}$ & $.786^{* *}$ & 1 \\
\cline { 2 - 7 } & $\mathrm{Sig}$ & .000 & .000 & .000 & .000 & \\
\cline { 2 - 7 } & $\mathrm{N}$ & 50 & 50 & 50 & 50 & 50 \\
\hline
\end{tabular}

Table 3. T-test of the variable skills of the test

\begin{tabular}{|c|c|c|c|c|c|c|c|}
\hline Variable & & $\mathrm{N}$ & Mean & Std. Deviation & T-test & Sig & Eta \\
\hline \multirow{2}{*}{ Pronunciation } & pre & 50 & 1.6800 & .68333 & \multirow{2}{*}{22.228} & \multirow{2}{*}{.000} & \multirow{2}{*}{.895} \\
\hline & post & 50 & 3.8800 & .38545 & & & \\
\hline \multirow{2}{*}{ Grammar } & pre & 50 & 1.5700 & .53462 & \multirow{2}{*}{20.843} & \multirow{2}{*}{.000} & \multirow{2}{*}{.902} \\
\hline & post & 50 & 3.7800 & .53605 & & & \\
\hline \multirow{2}{*}{ Vocabulary } & pre & 50 & .8800 & .23819 & \multirow{2}{*}{14.061} & \multirow{2}{*}{.000} & \multirow{2}{*}{.817} \\
\hline & post & 50 & 1.8400 & .42185 & & & \\
\hline \multirow{2}{*}{ Methods } & pre & 50 & 4.0600 & 1.15899 & \multirow{2}{*}{36.673} & \multirow{2}{*}{.000} & \multirow{2}{*}{.908} \\
\hline & post & 50 & 9.2400 & 1.25860 & & & \\
\hline \multirow{2}{*}{ Total } & pre & 50 & 8.1900 & 1.90833 & \multirow{2}{*}{44.676} & \multirow{2}{*}{.000} & \multirow{2}{*}{.948} \\
\hline & post & 50 & 18.7400 & 1.65443 & & & \\
\hline
\end{tabular}




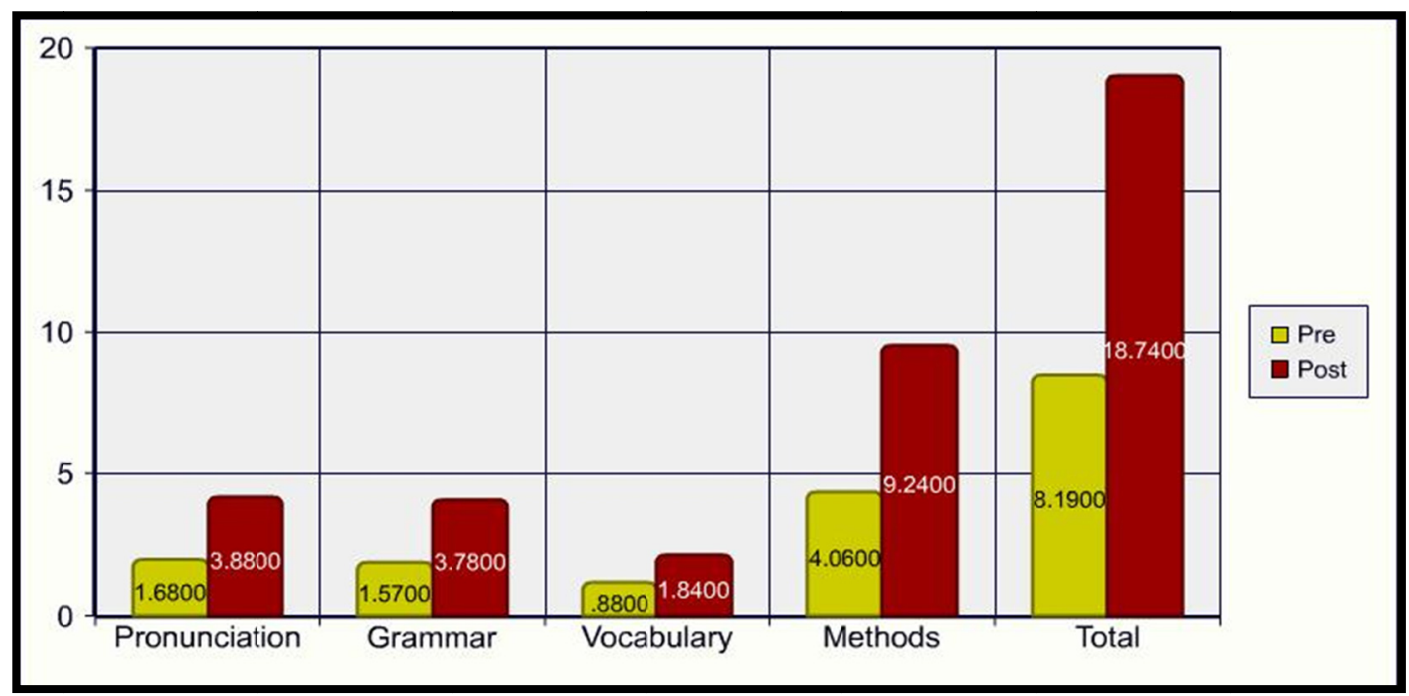

Figure 1. Total score of the pre-post test

\section{Results and Discussion}

The results of the pilot study and the questionnaire resulted in a number of topics to be included in the professional development program. The teachers were asked to arrange the program components they suggested in the pilot study according to their importance to them as language teachers. Teachers' responses to the questionnaire indicated that the following topics needed to be incorporated in the professional development program based on their needs: students' centered teaching techniques (multiple intelligences theory, learning styles, motivation, brainstorming, and error correction constructively), teaching grammar, vocabulary, and pronunciation, handling classroom management effectively, and planning and clarifying objectives.

The posttest revealed recognized enhancement in the four tested items, which indicates the effectiveness of the implemented program. Regarding pronunciation, results of the posttest show increase in teachers' performance in the posttest versus the scores of the pretest (see figure 1). This indicates the effectiveness of the program in relation to pronunciation. As students were allowed ample opportunities to use the language in different contexts through the mini dialogues they were asked to compose and rehearse with their colleagues, the use of different formats (drama, small group projects, individual, pair and small groups' presentations) enhanced their pronunciation skills noticeably. Emphasizing fluency rather than accuracy urged them to focus on expressing their thoughts and to let go of their ideas, which had a tremendous influence on their pronunciation. The sense of community that was created in the class and the scaffolding they got and the support of their teammates helped them to break their fear of the language, which helped their pronunciation greatly.

The scores of the posttest also indicated remarkable increase regarding vocabulary use (see figure 1) as the participants were allowed different opportunities to expand their repertoire of vocabulary through interactive activities that enable them to use new vocabulary in different contexts. They were given activities that encourage the use of what is called "smart vocabulary" to help students to use more elaborate vocabulary aside from the ones they are familiar with and practiced activities that entail giving scores and sometimes prizes to their students for using advanced vocabulary. The participants showed great enthusiasm to participate in the vocabulary activities as competition, collaboration, and rewards increased the level of participation and resulted in noticeable increase in their vocabulary, which was manifested in their scores in the posttest.

As for grammar, the scores of the participants revealed increase in the posttest, which indicates the effectiveness of the program on that component. The activities given to students focused on the application of different grammatical rules, especially those rules that were identified in participants' writings to be the ones they need to practice. The scores indicated increase in their actual application of rules of grammar, which was revealed in their presentations and explanation of students- centered approaches to grammar teaching (see figure 1).The enhancement manifested in the results varied among tested skills. Regarding pronunciation, it was noticed that it was the least skill developed which could be explained in terms of its need for a longer duration for a noticeable change to take place as it has fossilized along years of incorrect use and inappropriate training. The same holds true to vocabulary, and grammar which showed some development but were also less than the substantial 
development manifested in the methods part, which was enhanced due to the program implemented and this could be explained in light of the continued practice the participants received in both studying and applying the concepts introduced in the program. The application took various forms: in their small groups' presentations, projects, and class discussions. The use of different formats allowed the participants to work on introduced skills over and over again and to polish them so they were competent and this was translated in the improvement that took place in their responses to the questions posed in the posttest. Tables 1,2 , and 3 show the increase in the scores related to the 4 skills under investigation. The Program was effective in relation to the items suggested by the teachers who participated in the study, which were incorporated into the program.

Students were given home assignments that aimed at allowing them an opportunity to practice the items suggested. Then those items were practiced again in the class through class discussions and class activities to enhance their skills in relation to the suggested items. Research, projects, presentations, and teamwork constituted a big part of the program. Encouraging students to express their ideas in English occupied an important part of class time through continuous class discussions of new concepts and applications. Allowing students to capitalize on their strengths through exploring their intelligences and learning styles, with the aim of having a first-hand experience of what they should do in their teaching. Creating a learning community that is safe and enriched is another skill teachers worked hard to develop through taught post graduate course.

The results of the current study coincided with the results of studies conducted in different parts in the Arab world, and worldwide which urged for a needed reform in teacher training in general and English induction courses in specific. This verifies the need for real investment in induction courses that are based on teachers' needs and that aim at raising the skills and knowledge of teachers through effective pre-service and in-service professional development courses.

\section{Conclusions, Interpretations and Implications}

A substantial number of teachers did not have good command of the language, which hindered their efficacy in the class, however a noticeable enhancement took place as a result of the application of the program, which was clearly manifested in their performance in the posttest versus the pretest in which they were mostly able to identify the problem but unable to find a solution (See appendix $2 \& 3$ ). On the other hand, the posttest reflected better understanding of the concepts presented in the program, which allowed them to identify the problem and find solutions in most cases. Their awareness of the concepts and their handling of different situations in the classroom improved tremendously. A substantial number of participants showed willingness to apply more students- centered teaching approaches and were better able to select teaching strategies compatible with students' diverse abilities and skills. In sum, the majority manifested deeper understanding of the concepts taught, and they were willing to change their ways and apply more interactive students- centered teaching strategies especially the ones presented in the course. Some teachers took the initiative of applying novice teaching techniques they explored themselves, which they proudly shared with the instructor and the rest of the class. A few showed an inclination to regress to their old teacher -centered approaches, which they mastered and felt more at home with. Results indicated that though there were improvements in the participants' language skills "listening, speaking, reading and writing", due to the application of authentic activities, which allowed them to use the language in different forms, their pronunciation, grammar, vocabulary seemed to need more time for more improvements to take place.

\section{Recommendations}

The study recommends working on students' attitudes and language abilities early on in both pre-service and in-service education programs. Incorporating authentic activities, encouraging students to use the language and to express themselves in English in different formats enhance their listening, reading, speaking and writing. Moreover, it encourages students' self-confidence and self-esteem when speaking English. Involving students in writing course objectives, selecting the topics to be studied and course activities ensures students sense of ownership, which enhances their motivation and urges them to be fully invested in what they do, which in turn increases attendance rates and students participation in in-class and out of class activities. Team work, working in pairs and individually allows different participation types and gives the chance to shy students to participate more in small groups and in pairs without feeling that they are being put on the spot.

As graduates of colleges other than schools of education work in teaching in general and English teaching in specific, having set standards for their preparation and certification requirements are needed to ensure quality of teaching. Accreditation is another means for ensuring having qualified teachers. 


\section{References}

Albaiz, T. (2016). Enhancement of higher education teaching of English in Saudi Arabia. US-China Education Review A, 6(6), 327-344.

Alhabahba, M., Pandian, A., \& Mahfoodh, O. (2016). English language education in Jordan: Some recent trends and challenges. Cogent Education. https://doi.org/10.1080/2331186X.2016.1156809

Armstrong, T. (1994). Multiple Intelligences in the classroom. Alexandria, Virginia: Association for Supervision and Curriculum Development.

Belhiah, H., \& Elhami, M. (2015). English as a medium of instruction in the Gulf: When students and teachers speak. Lang Policy, 14, 3-23. https://doi.org/10.1007/s10993-014-9336-9

Bickart, T., Jablon, J., \& Dodge, D. (2004). Building the primary classroom: A Complete guide to teaching and learning. Portsmouth, NH: Heinemann.

Brown, C. (2007). Impact of professional development on teaching limited English proficient students in a suburban school district. Wayne State University, ProQuest Dissertations Publishing.

Campbell, R., \& Ryles, G. (2013). Teaching English grammar: A handbook for Australian teachers. Australia: Pearson.

Chang, T. (2012). Using no child left behind waivers to improve English language learner education. Center for American Progress. Retrieved from http://files.eric.ed.gov/fulltext/ED535546.pdf

Ching, C. (2002). A Survey of Practices and Beliefs of Fifth and Sixth Grade English Teachers Concerning Elementary English Education in Taiwan. University of South Dakota, Proquest, UMI Dissertation Publishing.

Clark, K., \& Graves, M. (2005). Scaffolding students' comprehension of text. The Reading Teacher, 58(6), 570-580. Published by: International Reading Association Stable. https://doi.org/10.1598/RT.58.6.6

Crow, S. What motivates a lifelong learner? School Libraries Worldwide, 12(1), 22-34.

Derwing, T., \& Munro, M. (2009). Putting accent in its place: Rethinking obstacles to communication. Language Teaching, 42(4), 476-490. https://doi.org/10.1017/S026144480800551X

Gardner, H. (2004). Frames of mind: The theory of Multiple Intelligences. New York: Basic Books.

Gere, A., \& Berebitsky, D. (2009). Standpoints: Perspectives on highly qualified English teachers. Research in the Teaching of English, 43(3), 249-250.

Goddard, R. G., Hoy, W. K., \& Hoy, A. W. (2000). Collective teacher efficacy: Its meaning, measure, and impact on student achievement. American Educational Research Journal, 37, 479-508. https://doi.org/10.3102/00028312037002479

Huang, J. (2004). Knowledge of English phonological and phonic patterns: An examination between pre-service elementary school teachers in Taiwan and in the United States. Unpublished PhD Dissertation. College of Graduate Studies, University of Idaho.

Hye-Sook, L. (2014). The intersection between professional development and professional learning communities: Working towards improving the educational experiences of English learners. University of Maryland, Baltimore County, ProQuest Dissertations Publishing.

Javid, K. (2014). Perceptive determination of Saudi EFL learners about the characteristics of an ideal English language teacher. Research on Humanities and Social Sciences, 4(8).

Jensen, E. (1998). Teaching with the brain in mind. Alexandria, Virginia: Association for Supervision and Curriculum Development.

Lam, T. (2011). The impact of Vietnam's globalization on national education policies and teacher training programs for teachers of English as an international language: A case study of the University of Pedagogy in Ho Chi Minh City (Unpublished PhD Dissertation). Hufstedler School of Education, Alliant International University. UMI Number: 3463876.

Lantolf, J. (2000). Introducing Sociocultural Theory. In J. Lantolf (Ed.), Sociocultural Theory and Second Language Learning. UK: Oxford University Press.

Lauren, M. (2012). Talking to learn: A Mixed-methods study of a professional development program for teachers of English language learners. University of California, Irvine, ProQuest Dissertations Publishing. 
Maguire, M. (2000). Inside/outside the ivory tower: Teacher education in the English academy. Teaching in Higher Education. https://doi.org/10.1080/135625100114812

No Child Left Behind Act of 2001. (n.d.) U.S. department of Education. Retrieved from http://www2.ed.gov/nclb/overview/intro/index.html?exp=5

O'Hara, S., Pritchard, R., \& Zwiers, J., (2012). Identifying academic language demands in support of the common core standards. Best Practices for Teaching ELLs, 7(17). Retrieved from http://www.ascd.org/ascd-express/vol7/717-ohara.aspx

Orr, M. (2011). Learning to teach English as a foreign language in Lebanon. Near and Middle Eastern Journal of Research in Education, 2011(2).

Parrish, T. B., Perez, M., Merickel, A., \& Linquanti, R. (2007). Research review: What research says about preparing English language learners for academic success. Retrieved from https://www.shastacoe.org/uploaded/Dept/is/general/Teacher_Section/EnglishLanguageLearners.pdf

Plavin, S. (2004). Retention and induction of newly qualified primary English teachers in Israel (PhD Thesis. Department of Education, University of Leicester). Published by ProQuest LLC 2013UMI U205077

Reineke, J., Sonsteng, K., \& Gartrell, D. (2008). Nurturing mastery motivation: No need for rewards. Young Children Nov, 89-97.

Richards, J., \& Lockhart, C. (1997). Reflective teaching in second language classrooms. USA: Cambridge University Press.

Shuang-Mei, W. (2011). A study on the professional development of college English teachers from the perspective of learning organization. Central South University (People's Republic of China), ProQuest Dissertations Publishing.

Snyder, G., \& Snyder, M. (2008). Teaching critical thinking and problem solving skills. Delta Pi Epsilon Journal, 50(2), 90-100.

Tanaka, M. (2008). Native and nonnative teachers working collaboratively: How perceptions and roles affect teacher discourse in Japanese elementary school English language classrooms. University of California, Santa Barbara, ProQuest Dissertations Publishing.

Woolley, G. (2011). Reading comprehension: Assisting children with learning difficulties. Springer Science +Business Media, 131-146.

Young, P. (2013). An exploration of teachers' perceptions regarding the professional needs of English immersion teachers in Korea. Indiana University, ProQuest, UMI Dissertations Publishing.

Zhi-Ying, Z. (2010). Research on junior high school English teachers' needs for professional development. East China Normal University (People's Republic of China), ProQuest Dissertations Publishing.

\section{Appendix 1(A)}

\section{Open Questionnaire}

Please answer the following question:

What are your expectations from the Methods of English Teaching course based on your needs as an English Teacher?

\section{Appendix 1(B)}

\section{Directed Questionnaire}

The open questionnaire you filled resulted in the following items being the most important in designing a professional development program for English teachers; please arrange the following components according to their importance to you as an English teacher by putting number 1 between brackets next to the most important item, then number 2 , etc.

Students-centered teaching Approaches (e.g. Multiple Intelligences Theory-Cooperative Learning).

Incorporating Technology in English Teaching.

Techniques for Teaching Higher order thinking skills.

Methods for teaching language skills: Listening, speaking, reading and writing. 
Evaluation Techniques (assessment).

Planning for your teaching.

Examples of some classroom activities (applications in the classroom etc.).

Classroom management techniques (practical suggestions for dealing with behavioral problems inside the classroom, such as discipline, violence, etc.

Language lab (auditory and visual) phonetics.

Demos (projects and presentations) mini lessons to practice theories and methods.

Psychological and emotional needs of the learners.

Methods for teaching grammar, vocabulary and reading.

How to deal with students' individual differences.

Using English language in teaching English.

Students' developmental characteristics.

Please feel free to add any component that needs to be added to the program from your point of view.

Thank you for your cooperation

\section{Appendix 2}

\section{Pre-Post Test}

To assess teachers' knowledge of the content of Methods of Teaching English Program

The following situations are examples of some challenges that teachers might encounter on their daily teaching experiences. Please write your comments on the way you think teachers need to handle these situations: Refer to your readings in the program (in the post-test):

1. Your students in the classroom are pronouncing /s/ sound similarly in the words "bones" /z/, desks /s/ and "classes"/iz/, how can you solve this problem?

2. A big number of your students add the vowel /e/ before /s/ when they pronounce the words "students" /studentes/, "girls" /girles/, and "combs" /kombez/

How can you correct this persistent error?

3. Some students in one of your classes are confused about the appropriate use of prepositions among, and between. They write the following sentences:

1) I was sitting between all my friends in my birthday party.

2) My seat in the cinema was in the middle among the two front rows.

Correct them and give reason.

4. Some students confuse past and present tenses when they are asked to write an essay.

1) Yesterday I go to club with my friend Perihan.

2) Today I played football and had a wonderful time with my relatives.

Correct them and give reason.

5. Teacher puts a list of new words on the board with their Arabic translation. The other teacher gives some new words and asks students to brainstorm other related words.

Which method is better? Why?

6. A teacher explains the lesson without mentioning its objectives. List the disadvantages of this practice.

7. A teacher provides a variety of authentic activities: shows a movie, draws some pictures and diagrams, and asks students to role play characters in the lesson presented. The other teacher focuses only on the exercises of grammar in the textbook.

Which activities do you prefer? Why?

8. You are entering two classes:

The first one is quiet. Students are sitting in rows, and they are not talking or interacting with one another. The teacher talks most of the time and the students are listening and taking notes. 
The second class is noisy: students are sitting in groups, talking and interacting with each other, presenting and teacher guides them, and gives direction.

Which class is better? Why?

9. One of your students is making errors. One teacher embarrassed him. Another teacher gave more examples on the teaching point, and modeled the right answer.

Which class do you prefer? Why?

10. One student is standing most of the time, making comments, and moving around the class. He got on your nerves.

How can you face this problem? Give examples.

\section{Appendix 3}

\section{Description of Pre and Post Tests \& Criteria for assessing teachers' answers}

The test includes 10 situations that represent challenges that teachers might encounter in their daily teaching experiences. Teachers are asked to write their comments on the way they think they would handle such situations in reference to their readings in the Methods course. The 10 items were distributed as follows: 2 items for pronunciation, 2 for grammar, 1 for vocabulary, and 5 items for students- centered teaching techniques that focus on having clear objectives, using authentic activities, brainstorming, role play, movies, presentations, group work, error correction constructively, and finally applying effective classroom management techniques. Students were given one mark for correctly identifying the problem, and one mark for suggesting a solution to the problem posed. Total marks for each domain were calculated and listed in a table. These marks represented the increase in the knowledge and skills gained by participants in the study in relation to the concepts presented in the course.

The two questionnaires and the pre and post tests were given to jury to assess their validity and reliability.

\section{Appendix 4}

\section{Course Description for the Methods of Teaching English Program Based on Students' Needs}

\section{Course Description:}

The overall goal of this course is to help the teachers achieve a deeper understanding of how preparatory and secondary students learn and of the pedagogic models and practices specific to their subject area teaching and learning. Topics covered include: knowledge and skills in using instructional strategies and classroom organizational models; how to develop their understanding of how their student's diverse learning styles can affect learning and teaching; how to develop the critical thinking, problem solving and performance skills of their students; and how to create a supportive, motivating, enriched and safe learning environment. Classroom management will be covered in relation to adolescent students who are characterized by a range of beliefs, knowledge, experience and interests.

\section{Course Goals:}

1) To adopt an outlook to the classroom as a learning community that needs to be safe, inclusive, motivating, and enriched

2) To encourage learners to develop an attitude and ability that prompts them to become lifelong learners.

3) To provide appropriate scaffolding that help students advance beyond their current developmental stage.

4) To implement teaching strategies that enhance learners' critical thinking and problem solving skills.

5) To develop an awareness of the positive impact of the enriched environment on learners' brains and consequently on their achievement.

6) To minimize the negative impact created by stress and threats on students' brains and behaviors.

7) To adapt teaching strategies to learners' multiple intelligences and learning styles.

8) To utilize effective classroom management strategies.

9) To improve students' pronunciation through allowing them various chances to use the oral language in different contexts.

10) To allow students to use more elaborate vocabulary in different contexts.

Measurable Objectives:

By the end of the course, you should be able to: 
1) Vary instructional strategies to accommodate learners' various intelligences and learning styles.

2) Create a learning community that is safe, enriched and motivating.

3) Instill in learners the attitudes that help them become lifelong learners.

4) Scaffold students by providing them with the support that is appropriate to their developmental stage.

5) Implement effective classroom management techniques.

6) Enhance students' pronunciation by providing models for accurate pronunciation and allowing students ample opportunities to practice.

7) Enable students to work on their persistent grammatical mistakes through peer and group work activities that involve the application of the rules in different contexts.

8) Encouraging students to expand their repertoire of vocabulary through written and oral activities.

\begin{tabular}{|c|c|c|}
\hline $\begin{array}{ll}1 \\
\text { Feb } 16\end{array}$ & Multiple Intelligences & Armstrong (pp. 37-47) \\
\hline $\begin{array}{l}2 \\
\text { Feb } 23\end{array}$ & MI and Curriculum Development & Armstrong (pp. 48-64) \\
\hline $\begin{array}{l}3 \\
\text { March } \\
2^{\text {nd }} \\
\end{array}$ & MI and Teaching Strategies & Armstrong (pp. 65-85) \\
\hline $\begin{array}{l}4 \\
\text { March } 9^{\text {th }}\end{array}$ & Motivation and Rewards & $\begin{array}{l}\text { Jensen (pp. 62-70), Reineke, Sonsteng, and } \\
\text { Gartrell (pp. 89-97) }\end{array}$ \\
\hline $\begin{array}{l}5 \\
\text { March } \\
16^{\text {th }}\end{array}$ & What motivates a lifelong learner? & Crow (pp. 22-34) \\
\hline $\begin{array}{l}6 \\
\text { March } \\
23^{\text {rd }}\end{array}$ & $\begin{array}{l}\text { Vygotsky's Zone of Proximal Development: Scaffolding Students' } \\
\text { Comprehension of Text }\end{array}$ & Clark and Graves (pp. 570-580) \\
\hline $\begin{array}{l}7 \\
\text { March } \\
30^{\text {th }}\end{array}$ & Enriched Environments and the Brain & Jensen (pp. 29-40) \\
\hline $\begin{array}{l}8 \\
\text { April } 6^{\text {th }}\end{array}$ & How Threats and Stress Affect Learning & Jensen (pp. 52-61) \\
\hline $\begin{array}{l}9 \\
\text { April } \\
\text { 13th }\end{array}$ & Teaching Critical Thinking and Problem Solving Skills & Snyder and Snyder (pp. 90- 100) \\
\hline $\begin{array}{l}10 \\
\text { April } \\
20 \text { th }\end{array}$ & Classroom Management Techniques & Bickart (pp. 80- 88) \\
\hline $\begin{array}{l}11 \\
\text { April } 27^{\text {th }}\end{array}$ & Teaching English Grammar & Campbell (2013, Ch. 1 \& 3) \\
\hline $\begin{array}{l}12 \\
\text { May 4th }\end{array}$ & Teaching English Pronunciation & Derwing (pp. 264-290) \\
\hline
\end{tabular}

\section{Copyrights}

Copyright for this article is retained by the author(s), with first publication rights granted to the journal.

This is an open-access article distributed under the terms and conditions of the Creative Commons Attribution license (http://creativecommons.org/licenses/by/4.0/). 